\title{
GMR
}

\section{Association of single nucleotide polymorphisms in pro-inflammatory cytokine and toll-like receptor genes with pediatric hematogenous osteomyelitis}

\author{
A.E. Osman ${ }^{1}$, M. Mubasher ${ }^{1}$, N.E. EISheikh ${ }^{1}$, H. AlHarthi ${ }^{1}$, M.S. AlZahrani ${ }^{1}$, \\ N. Ahmed ${ }^{1}$, G. ElGhazali ${ }^{2}$, B.A. Bradley ${ }^{3}$ and A.-S.A. Fadil ${ }^{1}$ \\ ${ }^{1}$ King Fahad Medical City, Riyadh, Saudi Arabia \\ ${ }^{2}$ Mafraq hospital and Sheikh Khalifa Medical city, Abu Dhabi, \\ United Arab Emirates \\ ${ }^{3}$ Musculoskeletal Research Unit, First Floor Learning and Research Building, \\ Southmead Hospital, University of Bristol, Bristol, United Kingdom \\ Corresponding author: A.E. Osman \\ E-mail: awadelsid@yahoo.com \\ Genet. Mol. Res. 15 (2): gmr. 15027718 \\ Received September 23, 2015 \\ Accepted December 10, 2015 \\ Published May 23, 2016 \\ DOI http://dx.doi.org/10.4238/gmr.15027718
}

\begin{abstract}
Hematogenous osteomyelitis $\left(H_{\mathrm{O}}\right)$ is a bone infection wherein bacteria penetrate to the bone through the blood stream. Several single nucleotide polymorphisms (SNPs) have been associated with susceptibility to infectious diseases. In this study, we investigated the contribution of SNPs in interleukin (IL)-1B1 (rs16944), IL1A (rs1800587), IL1B (rs1143634), toll-like receptor (TLR)-2 (rs3804099), TLR4 (rs4986790), TLR4 (rs4986791), IL1R (rs2234650), tumor necrosis factor (TNF)- $\alpha$ (rs1800629), TNF (rs361525), and IL1RN (rs315952) towards the development of $H_{\mathrm{O}}$ in Saudi patients and compared to healthy controls. Fifty-two patients diagnosed with $H_{\mathrm{O}}$ and 103 healthy individuals were genotyped. The frequencies of genotypes GG (rs16944) and AA (rs16944) were lower and higher in patients
\end{abstract}


[odds ratio $(\mathrm{OR})=0.34, \mathrm{Pc}=0.05]$ and controls $(\mathrm{OR}=1.33, \mathrm{Pc}=$ $0.05)$, respectively, suggesting that SNPs at this locus could alter $H_{\mathrm{O}}$ susceptibility. In addition, the patients and controls exhibited lower and higher frequencies of the alleles $\mathrm{G}(\mathrm{rs} 16944)(\mathrm{OR}=0.43, \mathrm{Pc}=0.007)$ and $\mathrm{A}(\mathrm{rs} 16944)(\mathrm{OR}=2.32, \mathrm{Pc}=0.007)$, respectively. The expression of alleles C (rs3804099) and T (rs3804099) were higher in patients (OR $=2.05, \mathrm{Pc}=0.04)$ and controls $(\mathrm{OR}=0.49, \mathrm{Pc}=0.04)$, respectively. In conclusion, SNPs at rs 16944 and rs3804099 were found to be associated with $H_{\mathrm{O}}$ in the Saudi population.

Key words: Pro-inflammatory; Cytokines; Osteomyelitis; Nucleotide; Polymorphisms

\section{INTRODUCTION}

Hematogenous osteomyelitis $\left(H_{\mathrm{O}}\right)$ is a bacterial bone infection characterized by progressive inflammatory destruction, caused by microorganisms that reach the bones through the blood stream. Staphylococcus aureus is the most common pathogenic organism causing $H_{\mathrm{O}}$, although Streptococci, gram-negative enteric organisms, and anaerobic bacteria have also been linked to the disease (Lew and Waldvogel, 1997; Beckles et al., 2010; Al Hajry et al., 2012). Infection typically occurs in children, and is commonly caused by invasion of the richly vascularized metaphyseal region of the tibia, femur, or humerus by a single microorganism (Claro et al., 2011). Previous studies have suggested that the frequency of acute osteomyelitis is higher in children in Saudi Arabia than in other parts of the world (Blyth et al., 2001; Riise et al., 2008; Al Hajry et al., 2012).

Many genes have the ability to regulate the immune system, thereby playing important roles in natural host defense against microbial pathogens in the bodily tissues or blood (Hill, 2012). Non-self pathogenic products, or pathogen-associated molecular patterns (PAMPs), interact with pattern recognition receptors (PRRs) to produce a signal that causes an increase in pro-inflammatory cytokine secretion. Binding of PAMPs to PRRs such as Toll-like receptors 2 and 4 (TLR-2 and TLR-4) initiates the transcription of pro-inflammatory cytokines such as interleukin 1 (IL-1 $\beta$ ) and tumor necrosis factor alpha (TNF- $\alpha$ ) (Gogos et al., 2000; Montes et al., 2006; Christaki and Giamarellos-Bourboulis, 2014). These cytokines activate the host immune system to eliminate the infectious pathogens. The excessive release of proinflammatory cytokines inhibits tissue regeneration and facilitates auto-immunity. Therefore, inflammation is tightly regulated (Reale et al., 2011). Single nucleotide polymorphisms (SNPs) are the most common genetic variations occurring in humans. They are located within the coding and promoter regions of genes, and thereby affect gene function. Several SNPs are associated with susceptibility to infectious disease (Lu et al., 2005; Reale et al., 2011; Oliveira et al., 2012; Christaki and Giamarellos-Bourboulis, 2014). Although their functional role remains to be established, several SNPs are believed to affect the production of cytokines (Tsezou et al., 2008). Certain SNPs, such as those located within TLR-4 and IL-1B, have been shown to be associated with vulnerability to osteomyelitis (Arend et al., 2001; Sasaki et al., 2002; Montes et al., 2006; El-Shanti and Ferguson, 2007; Tsezou et al., 2008).

In this study, a panel of SNP loci (Table 1) was genotypes in Saudi children with $H_{\mathrm{O}}$, in order to identify variants associated with $\mathrm{HO}$ that might be involved in immune system modulation and susceptibility to infection. 
Table 1. Cytokine, cytokine receptor, and toll-like receptor characteristics (Lu et al., 2005; Tsezou et al., 2008; Jotanovic et al., 2012; Zheng et al., 2013)].

\begin{tabular}{|c|c|c|c|c|c|c|}
\hline Gene & Gene Name & Chromosome & SNP ID & Polymorphism & Haplotypes & $\begin{array}{c}\text { Dye tagged with probe } \\
\text { [VIC/FAM] }\end{array}$ \\
\hline$I L 1 B$ & Interleukin $1-\beta$ & \multirow[t]{5}{*}{2} & rs16944 & $\mathrm{G} / \mathrm{A}$ & GG/GA/AA & [G/A] \\
\hline$I L 1 A$ & Interleukin- $\alpha$ & & rs 1800587 & $\mathrm{~A} / \mathrm{G}$ & $\mathrm{AA} / \mathrm{AG} / \mathrm{GG}$ & $\overline{\mathrm{A} / \mathrm{G}]}$ \\
\hline$I L 1-R$ & Interleukin-R & & rs2234650 & $\mathrm{C} / \mathrm{T}$ & $\mathrm{CC} / \mathrm{CT} / \mathrm{TT}$ & {$[\mathrm{C} / \mathrm{T}]$} \\
\hline ILIRN & Interleukin 1 receptor antagonist & & rs 315952 & $\mathrm{C} / \mathrm{T}$ & $\mathrm{CC} / \mathrm{CT} / \mathrm{TT}$ & {$[\mathrm{C} / \mathrm{T}]$} \\
\hline$I L 1 B$ & Interleukin 1 B & & rs1143634 & $\mathrm{G} / \mathrm{A}$ & GG/GA/AA & {$[\mathrm{G} / \mathrm{A}]$} \\
\hline TLR2 & Toll-like receptor 2 & 4 & rs3804099 & $\mathrm{C} / \mathrm{T}$ & $\mathrm{CC} / \mathrm{CT} / \mathrm{TT}$ & {$[\mathrm{C} / \mathrm{T}]$} \\
\hline$T N F-A$ & Tumor necrosis factor alpha & \multirow[t]{2}{*}{6} & rs1800629 & $\mathrm{A} / \mathrm{G}$ & $\mathrm{AA} / \mathrm{AG} / \mathrm{GG}$ & {$[\mathrm{A} / \mathrm{G}]$} \\
\hline$T N F-A$ & Tumor necrosis factor alpha & & rs 361525 & $\mathrm{~A} / \mathrm{G}$ & AA/AG/GG & {$[\mathrm{A} / \mathrm{G}]$} \\
\hline TLR4 & Toll-like receptor 4 & \multirow[t]{2}{*}{9} & rs4986790 & $\mathrm{A} / \mathrm{G}$ & $\mathrm{AA} / \mathrm{AG} / \mathrm{GG}$ & {$[\mathrm{A} / \mathrm{G}]$} \\
\hline TLR4 & Toll-like receptor 4 & & rs4986791 & $\mathrm{C} / \mathrm{T}$ & $\mathrm{CC} / \mathrm{CT} / \mathrm{TT}$ & {$[\mathrm{C} / \mathrm{T}]$} \\
\hline
\end{tabular}

\section{MATERIAL AND METHODS}

\section{Patients and control subjects}

A total of 52 patients clinically diagnosed with $H_{\mathrm{O}}$ were recruited to this study. The diagnosis of $H_{\mathrm{O}}$ was confirmed by a group of tests, including $\mathrm{C}$ - reactive protein and erythrocyte sedimentation rate assays, culture of blood and fluid or pus from affected areas, X-ray, magnetic resonance imaging, and computerized tomography. Immunocompromised individuals, such as patients with sickle cell anemia or an autoimmune disease, were excluded from the study.

All patients were hospitalized at the Pediatric Orthopedic Department at King Fahad Medical City (KFMC), Riyadh, Saudi Arabia. One hundred and three healthy unrelated Saudi individuals admitted to the Emergency Department at KFMC for minor illness or symptoms, who agreed to participate in this study, were recruited as controls. None of the control participants had a history of $H_{\mathrm{O}}$, or were immunocompromised at the time of blood collection. The study was approved by the Institutional Review Board (IRB) of King Fahad Medical City (KFMC), and all participants or their guardians provided written informed consent. All procedures adhered to the rules and regulations of the government of Saudi Arabia, the KFMC/ IRB policies and procedures, and the IHC Good Clinical Practice guidelines.

\section{Genotyping}

A MagNA pure compact instrument (Roche Diagnostics Ltd., Rotkreuz, Switzerland) was used to extract genomic DNA from peripheral blood (stored in EDTA anti-coagulant tubes). DNA yields were measured using a Nanodrop ${ }^{\circledR} 2000 \mathrm{c}$ spectrophotometer (Thermo Scientific, Wilmington, DE, USA). Sequence-specific forward and reverse primers and two TaqMan ${ }^{\circledR}$ MGB probes with dyes (VIC/FAM) were used to detect allele 1 and allele 2 of each SNP (Applied Biosystems, Foster City, CA, USA). All procedures were performed according to the manufacturer protocols. The SNP alleles at each locus were separated using a Light Cycler ${ }^{\mathbb{B}} 480$ II (Roche Diagnostics Ltd.). Multiple DNA samples with known SNP genotypes were run in parallel with our study samples in order to ensure the quality of the analysis; similar results were obtained.

\section{Statistical analysis}

The conformance of the control data with the Hardy-Weinberg equilibrium (HWE) was 
analyzed by implementing the $\mathrm{X}^{2}$ distribution (degree of freedom $=1$ ), in order to indicate the differences between the expected and observed values of the tested SNPs, as described by Solé et al. (2006). The frequencies of alleles and genotypes for each SNP were derived by an algorithm developed based on a direct counting method using the SAS program (Shelton et al., 2004); the results were expressed as percentages at 95\% confidence intervals (CI). Fisher's exact test and logistic regression method were used to compare patient and control results. The log of the odds (logit) for the presence of each SNP was calculated to determine the significance differences at an overall significance level of 0.05 . The Bonferroni correction was applied whenever necessary.

\section{RESULTS}

Fifty-two patients aged between 1 and 17 years (median age $=7.5$ years; $57.7 \%$ female) diagnosed with $H_{\mathrm{O}}$ and 103 healthy normal individuals (age range $=11-63$ years, median age $=32.3$ years; $57.3 \%$ female) were investigated in this study. Microorganisms including Staphylococcus aureus, methicillin-resistant Staphylococcus aureus (MRSA), and Streptococcus agalactiae group B were isolated from the growth culture medium, representing approximately $40 \%$ of the cases; approximately $44 \%$ of the cases were negative for these bacteria. The control samples did not deviate from the HWE for allelic SNPs. Significant differences were observed between the patient and control samples at the allele and/or genotype level for SNPs rs16944 and rs3804099. The frequency distribution of AA (rs16944) was significantly higher in patients than in controls, while the expression of the GG (rs16944) genotype was higher in controls than in patients (Table 2). Accordingly, the frequency of expression of the G (rs16944) and A (rs16944) alleles were significantly higher in the controls and patients, respectively. The AA (rs1800587) allele frequency was higher in patients, but did not satisfy our criteria after applying the Bonferroni correction. No additional significant differences were detected among other SNPs genotyped in this study.

\section{DISCUSSION}

To the best of our knowledge, this is the first study reporting an association between SNPs in pro-inflammatory cytokine and TLR genes and $H_{\mathrm{O}}$ in the Saudi population. In this study, the results of the growth medium culture indicated that $S$. aureus was predominantly isolated from the study subjects. Approximately $44 \%$ of the samples were sterile, which we attribute to the use of antibiotic medications at the time of sample collection.

A total of 10 SNPs from different loci previously reported in association with infection, autoimmunity, and cancer were genotyped. Based on the obtained values, we concluded that the GG rs $16944(\mathrm{P}=0.005, \mathrm{Pc}=0.05)$ and the $\mathrm{G}$ rs $16944(\mathrm{P}=0.0007, \mathrm{Pc}=0.007)$ alleles were significantly less prevalent in patients than in controls; therefore, these alleles were considered to protect against $H_{\mathrm{O}}$. The frequency of expression of the AA rs $16944(\mathrm{P}=0.005, \mathrm{Pc}=0.05)$ and $\mathrm{A}$ rs16944 $(\mathrm{P}=0.0007, \mathrm{Pc}=0.007)$ alleles, on the other hand, were significantly higher in patients (approximately 4.2 and 2.3 times, respectively) than in controls, indicating this genotype and allele to be risk factors for this type of infection. Zheng et al. (2013) suggested that G rs16944 is associated with an increased risk of esophageal squamous cell carcinoma, while a meta-analysis of studies analyzing individuals of European descent Abu-Maziad et al. (2010) reported that osteomyelitis of the hand was associated with rs16944. However, Jotanovic et al. (2012) did not identify a significant association between this SNP and osteoarthritis in Caucasian patients. 


\begin{tabular}{|c|c|c|c|c|c|c|}
\hline Gene & SNP ID & Genotypes/Alleles & Patients $\%(\mathrm{~N}=52)$ & Control $\%(\mathrm{~N}=103)$ & OR $(95 \% \mathrm{CI})$ & P value \\
\hline \multirow[t]{5}{*}{ IL1BI } & \multirow[t]{5}{*}{ rs16944 } & GG & 23.1 & 46.6 & $0.34(0.16-0.73)$ & $0.005(\mathrm{Pc}=0.05)$ \\
\hline & & GA & 53.8 & 46.6 & $1.33(0.69-2.61)$ & 0.39 \\
\hline & & $\mathrm{AA}$ & 23.1 & 6.8 & $4.11(1.51-11.21)$ & $0.005(\mathrm{Pc}=0.05)$ \\
\hline & & $\mathrm{G}$ & 50 & $69.9 \%$ & $0.43(0.27-0.70)$ & $0.0007(\mathrm{Pc}=0.007)$ \\
\hline & & A & 50 & 30.1 & $2.32(1.42-3.76)$ & $0.0007(\mathrm{Pc}=0.007)$ \\
\hline \multirow[t]{5}{*}{ IL1A } & \multirow[t]{5}{*}{ rs 1800587} & AA & 44.2 & 27.2 & $2.12(1.05-4.27)$ & $0.034(0.34)$ \\
\hline & & $\mathrm{AG}$ & 34.6 & 46.6 & $0.61(0.3-1.21)$ & 0.16 \\
\hline & & GG & 21.2 & 26.2 & $0.76(0.34-1.67)$ & 0.49 \\
\hline & & $\mathrm{A}$ & 61.5 & 50.5 & $1.57(0.97-2.54)$ & 0.074 \\
\hline & & G & 38.5 & 49.5 & $0.64(0.39-1.03)$ & 0.07 \\
\hline \multirow[t]{5}{*}{$I L 1 B$} & \multirow[t]{5}{*}{ rs1143634 } & GG & 53.8 & 54.4 & $0.98(0.5-1.91)$ & 0.95 \\
\hline & & GA & 38.5 & 34 & $1.2(0.61-2.42)$ & 0.58 \\
\hline & & $\mathrm{AA}$ & 7.7 & 11.6 & $0.63(0.19-2.42)$ & 0.44 \\
\hline & & $\mathrm{G}$ & 73.1 & 71.4 & $1.08(0.64-1.84)$ & 0.75 \\
\hline & & A & 26.9 & 28.6 & $0.92(0.54-1.56)$ & 0.75 \\
\hline \multirow[t]{5}{*}{ TLR2 } & \multirow[t]{5}{*}{ rs3804099 } & $\mathrm{CC}$ & 42.3 & 26.2 & $2.1(1.0-4.17)$ & 0.44 \\
\hline & & $\mathrm{CT}$ & 50 & 47.6 & $1.1(0.57-2.15)$ & 0.78 \\
\hline & & TT & 8.7 & 26.2 & $0.23(0.08-0.71)$ & 0.011 \\
\hline & & $\mathrm{C}$ & 67.3 & 50 & $2.05(1.26-3.37)$ & $0.004(\mathrm{Pc}=0.04)$ \\
\hline & & $\mathrm{T}$ & 32.7 & 50 & $0.56(0.34-0.94)$ & $0.004(\mathrm{Pc}=0.04)$ \\
\hline \multirow[t]{5}{*}{ TLR4 } & \multirow[t]{5}{*}{ rs 4986790} & $\mathrm{AA}$ & 100 & 92.2 & $9.54(0.54-168.7)$ & 0.124 \\
\hline & & $\mathrm{AG}$ & 0 & 8.8 & $0.22(0.011-4.1)$ & \\
\hline & & GG & 0 & 0 & & \\
\hline & & A & 100 & 96.1 & $0.22(0.01-4.07)$ & 0.304 \\
\hline & & $\mathrm{G}$ & 0 & 3.9 & & \\
\hline \multirow[t]{5}{*}{ TLR4 } & \multirow[t]{5}{*}{ rs4986791 } & $\mathrm{CC}$ & 100 & 91.3 & $9.4(0.53-166.9)$ & 0.125 \\
\hline & & $\mathrm{CT}$ & 0 & 7.7 & & \\
\hline & & TT & 0 & 0 & & \\
\hline & & $\mathrm{C}$ & 100 & 96.1 & $9.4(0.54-164.9)$ & 0.125 \\
\hline & & $\mathrm{T}$ & & 3.9 & & \\
\hline \multirow[t]{5}{*}{$I L 1 R$} & \multirow[t]{5}{*}{ rs 2234650} & $\mathrm{CC}$ & 26.9 & 31.1 & $0.82(0.39-1.71)$ & 0.59 \\
\hline & & $\mathrm{CT}$ & 57.7 & 44.7 & $1.7(0.86-3.31)$ & 0.21 \\
\hline & & TT & 15.4 & 24.2 & $0.67(0.24-1.36)$ & 0.127 \\
\hline & & $\mathrm{C}$ & 55.8 & 53.4 & $1.1(0.69-1.71)$ & 0.69 \\
\hline & & $\mathrm{T}$ & 44.2 & 46.6 & $0.91(0.56-1.46)$ & 0.69 \\
\hline \multirow[t]{5}{*}{$T N F \alpha$} & \multirow[t]{5}{*}{ rs 1800629} & $\mathrm{AA}$ & 57.7 & 66.3 & $0.67(0.34-1.33)$ & 0.26 \\
\hline & & $\mathrm{AG}$ & 30.8 & 26 & $1.25(0.6-2.61)$ & 0.55 \\
\hline & & GG & 11.5 & 6.7 & $1.79(0.57-5.62)$ & 0.32 \\
\hline & & $\mathrm{A}$ & 73.1 & 80.1 & $0.67(0.39-1.17)$ & 0.16 \\
\hline & & $\mathrm{G}$ & 29.9 & 19.9 & $1.48(0.85-2.58)$ & 0.16 \\
\hline \multirow[t]{5}{*}{$T N F$} & \multirow[t]{5}{*}{ rs361525 } & $\mathrm{AA}$ & 96.2 & 86.4 & $3.65(0.79-16.8)$ & 0.1 \\
\hline & & $\mathrm{AG}$ & 3.8 & 12.6 & $0.27(0.06-1.26)$ & 0.11 \\
\hline & & GG & 0 & 1 & & \\
\hline & & A & 98.1 & 92.7 & $4.0(0.89-17.8)$ & 0.07 \\
\hline & & $\mathrm{G}$ & 1.9 & 7.3 & $0.25(0.06-1.13)$ & 0.07 \\
\hline \multirow[t]{5}{*}{$I L 1 R N$} & \multirow[t]{5}{*}{ rs315952 } & $\mathrm{CC}$ & 53.8 & 54.4 & $0.98(0.5-1.9)$ & 0.95 \\
\hline & & $\mathrm{CT}$ & 38.5 & 36.9 & $1.1(0.54-2.13)$ & 0.84 \\
\hline & & TT & 7.7 & 8.7 & $0.87(0.25,2.97)$ & 0.82 \\
\hline & & $\mathrm{C}$ & 73.1 & 72.8 & $1.01(0.59-1.7)$ & 0.96 \\
\hline & & $\mathrm{T}$ & 26.9 & 27.2 & $0.86(0.58-1.68)$ & 0.96 \\
\hline
\end{tabular}

The results of our study also indicated that the frequency of the C rs3804099 allele, located in TLR2, is significantly higher in patients than in control individuals $(\mathrm{P}=0.004$, $\mathrm{Pc}=0.04)$, indicating that people positive for this allele are at a twofold greater risk of $H_{\mathrm{O}}$ than negative individuals. In contrast, the frequency of the T rs3804099 allele was lower in the patients than in the control subjects $(\mathrm{P}=0.004, \mathrm{Pc}=0.04)$, with an odds ratio $<0.6$, suggesting that this allele confers protection against $H_{\mathrm{O}}$. In fact, TLRs are important cellular receptors involved in initiating the inflammatory response against invading microorganisms, 
and have the ability to recruit different intracellular adapter proteins in response to pathogenic infection. Montes et al. discovered a significant association between rs3804099 and grampositive infections; they hypothesized that mutations in TLR2 could reduce the response to gram-positive lipoproteins, thereby leading to a high risk of infection (Hill, 2012).

The variations detected in the SNPs included in our study suggest a modification of the inflammatory response. Additionally, the segregation of rs16944 and rs3804099 SNPs in two different genes shows that these loci may be subject to selective pressure in a $H_{\mathrm{O}}$ susceptible population.

In conclusion, despite the small sample size included in this study, we could detect an association between the rs16944 (G/A) and rs3804099 (C/T) SNPs and susceptibility to $H_{\mathrm{O}}$. One limitation of this study may be that other as-yet undiscovered genetic factors are in linkage disequilibrium with our findings; moreover, studies with a larger sample size are recommended to better understand the genetic markers associated with $H_{\mathrm{O}}$.

\section{Conflicts of interest}

The authors declare no conflict of interest.

\section{ACKNOWLEDGMENTS}

Research supported by the King Fahad Medical City, Riyadh, Saudi Arabia. Our thanks and appreciation are extended to the patients and donors who agreed to participate in this study; we would also like to thank Dr. Abduwahid Al-Dehaimi and the members of the immunology and serology laboratory at KFMC for their help and support.

\section{REFERENCES}

Abu-Maziad A, Schaa K, Bell EF, Dagle JM, et al. (2010). Role of polymorphic variants as genetic modulators of infection in neonatal sepsis. Pediatr. Res. 68: 323-329. http://dx.doi.org/10.1203/PDR.0b013e3181e6a068

Al Hajry M, Al Jumaah S and Almayouf SM (2012). Chronic recurrent multifocal osteomyelitis: a first report from Saudi Arabia. Ann. Saudi Med. 32: 611-614.

Arend SM, Janssen R, Gosen JJ, Waanders H, et al. (2001). Multifocal osteomyelitis caused by nontuberculous mycobacteria in patients with a genetic defect of the interferon-gamma receptor. Neth. J. Med. 59: 140-151. http:// dx.doi.org/10.1016/S0300-2977(01)00152-8

Beckles VL, Jones HW and Harrison WJ (2010). Chronic haematogenous osteomyelitis in children: a retrospective review of 167 patients in Malawi. J. Bone Joint Surg. Br. 92: 1138-1143.http://dx.doi.org/10.1302/0301-620X.92B8.23413

Blyth MJ, Kincaid R, Craigen MA and Bennet GC (2001). The changing epidemiology of acute and subacute haematogenous osteomyelitis in children. J. Bone Joint Surg. Br. 83: 99-102.http://dx.doi.org/10.1302/0301-620X.83B1.10699

Christaki E and Giamarellos-Bourboulis EJ (2014). The complex pathogenesis of bacteremia: from antimicrobial clearance mechanisms to the genetic background of the host. Virulence 5: 57-65. http://dx.doi.org/10.4161/viru.26514

Claro T, Widaa A, O'Seaghdha M, Miajlovic H, et al. (2011). Staphylococcus aureus protein A binds to osteoblasts and triggers signals that weaken bone in osteomyelitis. PLoS One 6: e18748. http://dx.doi.org/10.1371/journal. pone. 0018748

El-Shanti HI and Ferguson PJ (2007). Chronic recurrent multifocal osteomyelitis: a concise review and genetic update. Clin. Orthop. Relat. Res. 462: 11-19. http://dx.doi.org/10.1097/BLO.0b013e3180986d73

Gogos CA, Drosou E, Bassaris HP and Skoutelis A (2000). Pro- versus anti-inflammatory cytokine profile in patients with severe sepsis: a marker for prognosis and future therapeutic options. J. Infect. Dis. 181: 176-180. http://dx.doi. org $/ 10.1086 / 315214$

Hill AV (2012). Evolution, revolution and heresy in the genetics of infectious disease susceptibility. Philos. Trans. R. Soc. Lond. B Biol. Sci. 367: 840-849. http://dx.doi.org/10.1098/rstb.2011.0275 
Jotanovic Z, Etokebe GE, Mihelic R, Kaarvatn MH, et al. (2012). IL1B -511(G>A) and IL1RN (VNTR) allelic polymorphisms and susceptibility to knee osteoarthritis in Croatian population. Rheumatol. Int. 32: 2135-2141. http://dx.doi.org/10.1007/s00296-011-1946-3

Lew DP and Waldvogel FA (1997). Osteomyelitis. N. Engl. J. Med. 336: 999-1007. http://dx.doi.org/10.1056/ NEJM199704033361406

Lu CC, Sheu BS, Chen TW, Yang HB, et al. (2005). Host TNF-alpha-1031 and -863 promoter single nucleotide polymorphisms determine the risk of benign ulceration after H. pylori infection. Am. J. Gastroenterol. 100: 12741282. http://dx.doi.org/10.1111/j.1572-0241.2005.40852.x

Montes AH, Asensi V, Alvarez V, Valle E, et al. (2006). The Toll-like receptor 4 (Asp299Gly) polymorphism is a risk factor for Gram-negative and haematogenous osteomyelitis. Clin. Exp. Immunol. 143: 404-413. http://dx.doi. org/10.1111/j.1365-2249.2005.03002.x

Oliveira JG, Duarte MC and Silva AE (2012). IL-1ra anti-inflammatory cytokine polymorphism is associated with risk of gastric cancer and chronic gastritis in a Brazilian population, but the TNF- $\beta$ pro-inflammatory cytokine is not. Mol. Biol. Rep. 39: 7617-7625.http://dx.doi.org/10.1007/s11033-012-1596-x

Reale M, Patruno A, De Lutiis MA, Pesce M, et al. (2011). Dysregulation of chemo-cytokine production in schizophrenic patients versus healthy controls. BMC Neurosci. 12: 13. http://dx.doi.org/10.1186/1471-2202-12-13

Riise ØR, Kirkhus E, Handeland KS, Flatø B, et al. (2008). Childhood osteomyelitis-incidence and differentiation from other acute onset musculoskeletal features in a population-based study. BMC Pediatr. 8: 45. http://dx.doi. org/10.1186/1471-2431-8-45

Sasaki Y, Nomura A, Kusuhara K, Takada H, et al. (2002). Genetic basis of patients with bacille Calmette-Guérin osteomyelitis in Japan: identification of dominant partial interferon-gamma receptor 1 deficiency as a predominant type. J. Infect. Dis. 185: 706-709. http://dx.doi.org/10.1086/339011

Shelton BJ, Gilbert GH, Liu B and Fisher M (2004). A SAS macro for the analysis of multivariate longitudinal binary outcomes. Comput. Methods Programs Biomed. 76: 163-175.http://dx.doi.org/10.1016/j.cmpb.2004.05.005

Solé X, Guinó E, Valls J, Iniesta R, et al. (2006). SNPStats: a web tool for the analysis of association studies. Bioinformatics 22: 1928-1929. http://dx.doi.org/10.1093/bioinformatics/btl268

Tsezou A, Poultsides L, Kostopoulou F, Zintzaras E, et al. (2008). Influence of interleukin 1alpha (IL-1alpha), IL-4, and IL-6 polymorphisms on genetic susceptibility to chronic osteomyelitis. Clin. Vaccine Immunol. 15: 1888-1890. http://dx.doi.org/10.1128/CVI.00209-08

Zheng L, Yin J, Wang L, Wang X, et al. (2013). Interleukin 1B rs16944 G>A polymorphism was associated with a decreased risk of esophageal cancer in a Chinese population. Clin. Biochem. 46: 1469-1473. http://dx.doi. org/10.1016/j.clinbiochem.2013.05.050 